\title{
Regularização fundiária: perspectivas históricas e econômicas da cidade do Rio de Janeiro
}

\author{
Adjustment land: historical and economic \\ perspective of the city of Rio de Janeiro
}

\begin{abstract}
Andreza Aparecida Franco Câmara
Doutoranda no Programa de Pós-Graduação em Sociologia e Direito da Universidade Federal Fluminense (UFF), Mestre em Direito da Cidade pela Universidade do Estado do Rio de Janeiro (UERJ), professora assistente do curso de Direito da Universidade Federal Rural do Rio de Janeiro, Instituto Três Rios (UFRRJ/ITR), Rio de Janeiro, RJ - Brasil, e-mail: andrezaafc@hotmail.com
\end{abstract}

\section{Resumo}

O presente artigo objetiva abordar algumas questões fundamentais entre os problemas originados quanto ao uso do solo urbano e sua relação com a produção irregular de moradias. Além de discutir a reforma fundiária urbana e a segregação social nos assentamentos informais como resultado de algumas políticas públicas implementadas no município carioca, analisa os principais fatores do processo de segregação socioespacial na cidade do Rio de Janeiro, destacadamente nos anos setenta e oitenta. Contempla a crescente ideia da mercantilização do solo urbano pelos agentes econômicos e seus reflexos para 
a cidade ao longo de um processo histórico e econômico no Brasil, destacadamente na cidade carioca.

Palavras-chave: Regularização fundiária. Migração urbana. Uso do solo.

\section{Abstract}

This article aims to address some fundamental issues arising from problems in the use of urban land and its relation to abnormal production of housing. In addition to discussing land reform and social segregation in urban informal settlements as a result of some public policies implemented in the municipality of Rio, discusses the key factors in the process of socio-spatial segregation in the city of Rio de Janeiro, prominently in the seventies and eighties. Contemplates the idea of increasing commodification of urban land by economic agents and their consequences for the city over a historical process and economic development in Brazil, Rio prominently in the city.

Keywords: Settlement land. Urban migration. Land use.

\section{Introdução}

O presente artigo objetiva analisar a cidade do ponto de vista socioeconômico, podendo ser vista como o capital social materializado em bens, equipamentos e serviços valorizados, ou não, ao longo do tempo, gerando valores intangíveis. O desenvolvimento local é obtido por meio das ações institucionais e do capital social com a participação dos membros integrantes do espaço urbano. O conjunto de ações sociais que compõem a crescente capacidade econômica da cidade valoriza-se graças ao aprimoramento do capital humano, objetivando o aumento da qualidade de vida e a promoção do bem comum por meio da cooperação local.

Este trabalho busca contribuir para o entendimento e o encaminhamento dessas questões. Seu objetivo é avaliar os dados apresentados 
na dinâmica urbana da cidade do Rio de Janeiro no ano de 1978, possibilitando uma reflexão crítica sobre as principais políticas públicas de controle do crescimento urbano.

Desse modo, o objeto desse artigo é o estudo do processo de regularização fundiária na cidade carioca, analisando o contexto social e a dinâmica de ocupação do solo e refletindo, ainda, sobre a segregação dos espaços urbanos irregulares. O presente estudo tem o intuito de focalizar os parâmetros jurídico-institucionais que balizam as ações governamentais e o uso do solo, questionando as consequências para os assentamentos urbanos e a lógica do mercado imobiliário.

Pretende-se, ainda, analisar uma breve e panorâmica síntese para o leitor das condicionantes sociais, econômicas, culturais e políticas do processo de regularização fundiária fluminense sob uma perspectiva histórica, desde o Brasil colônia até a vigência do diploma urbanístico regulatório, denominado "Estatuto da Cidade", por meio da revisão da literatura especializada sobre o tema em estudo (DALLARI; FERRAZ, 2002). Além disso, intenta-se caracterizar as bases essenciais do processo de segregação socioespacial como resultado da dinâmica irregular de urbanização das áreas da periferia da cidade do Rio de Janeiro.

\section{Breve histórico do ordenamento fundiário brasileiro}

O processo de transformação do mundo medieval é marcado pela burguesia mercantil e as monarquias absolutistas, caracterizando o Estado com seus elementos configurativos. A figura estatal, detentora do monopólio do poder jurídico num determinado território em franca expansão e fortalecida pelo capitalismo mercantil, acarreta a centralização do poder monárquico, levando a uma corrida europeia pelo Atlântico em nome da fé e da expansão do reino.

Ao lado da motivação expansionista, o componente ideológico, urgência de levar a fé católica para os povos não cristianizados, move Portugal e Espanha, países que se notabilizam pelas descobertas de novos 
territórios. Durante a dinastia de Avis, no final do século XIV, o apoio sociopolítico da burguesia conduziu o empreendimento de novas rotas marítimas. Essa etapa desencadeia os primeiros conflitos entre as nações, principalmente após a notícia da existência de terras na América. As intensas negociações entre portugueses e espanhóis levaram mais de um ano após a recusa da primeira proposta papal para solucionar as disputas pelas terras americanas.

Em 7 de junho de 1494, foi assinado o Tratado de Tordesilhas, sendo ratificado somente em 24 de janeiro de 1504 pela Bula Pro Bono Pacis, de Julio II, determinando que a titularidade do solo existente a ocidente até 370 léguas a oeste do arquipélago de Cabo Verde seria de Portugal (MACEDO SOARES, 1939). A validade efetiva do tratado foi observada, contudo, pelos historiadores que questionam o sistema utilizado para efetuar a divisão prevista.

Com o descobrimento do território brasileiro, é marcada uma nova etapa na história no direito fundiário português. As novas terras foram incorporadas ao domínio português como um direito público real de propriedade, aplicando-se no Brasil a legislação da metrópole. Assim, teve início nossa "história territorial" (REIS, 2000, p. 18):

por ocasião do descobrimento do Brasil, as experiências de colonização que Portugal e os outros países europeus haviam realizado e tinham por cenário regiões habitadas por povos com certo grau de desenvolvimento econômico e cultural, capazes de oferecer gêneros de alto valor para os mercados da Europa e, ao mesmo tempo, de consumir produtos originários de suas manufaturas. Nessa categoria deve ser compreendida a conquista das Índias, que se constituía basicamente no estabelecimento de uma rede de feitorias, para garantir as linhas de comércio. ${ }^{1}$

1 Tupinambá Miguel Castro do Nascimento comenta que o Brasil “[...] surgiu como território colonial peculiar em face dos esquemas da expansão europeia. Encontrando na terra que acabavam de descobrir um território quase deserto, com população de baixo nível econômico e técnico, sem possibilidade de explorar, sem capacidade para absorver as manufaturas importadas da Europa e sem riquezas minerais das colônias espanholas, viram-se os portugueses na impossibilidade de 
Com o reconhecimento dominical português, os primeiros exploradores foram enviados à colônia para sua ocupação, monopolizando a área e fixando a soberania da metrópole. O primeiro interesse dos portugueses foi à riqueza do solo em decorrência da facilidade comercial. $\mathrm{O}$ crescimento comercial africano e indiano demonstrou-se mais importante do que as possibilidades e riscos da América.

A primeira expedição foi liderada por Martim Afonso de Sousa, em 1530, percorrendo da foz do Amazonas ao estuário do rio da Prata (IGLESIAS, 1993). O objetivo dessa expedição foi dar início à colonização portuguesa no Brasil. Após percorrer grande parte da costa brasileira, Martim Afonso fundou a primeira vila, denominada São Vicente em 1532, no litoral de São Paulo (REIS, 2000). A prosperidade das terras brasileiras ajudou a diminuir a hesitação da coroa portuguesa diante da oportunidade de ocupar o solo brasileiro.

Diante desse cenário, Dom João III aplica na colônia o sistema já experimentado nas terras africanas e orientais: o regime de capitanias hereditárias. Entre os anos 1534 e 1536, o Brasil foi dividido em 14 faixas de terra que se estendiam do litoral das terras do Atlântico até o interior, em largura que variava em até cem léguas; posteriormente, o número de capitanias cresceu. O benefício da doação das terras pelo governo português se estendia aos herdeiros daqueles sesmarianos, mas a transferência do domínio ficava sujeita às condições resolutivas, sendo elas: a lavra, a adubação e o aproveitamento do solo, conforme se registra nas três cartas régias do monarca ${ }^{2}$ (NASCIMENTO, 1985).

aplicação daqueles esquemas, com a mesma amplitude, ao caso brasileiro. Durante as primeiras décadas após o descobrimento, limitaram-se a uma exploração grosseira dos recursos naturais. Esse sistema deu origem às primeiras feitorias e alguns agrupamentos de brancos, com rudimentos de agricultura, povoados na sua maioria por náufragos".

2 Tupinambá Miguel Castro do Nascimento informa que ao "executar a política de colonização das terras do Brasil, Portugal a executa, se estribando em fórmulas já experimentadas na metrópole. A colocação histórica feita por Marcello Caetano é verdadeira: "Perante o problema de colonizar as novas terras descobertas o Rei de Portugal, portanto, utilizou soluções já antes experimentadas", visto que "quando D. João III resolve ocupar-se da colonização do Brasil, estende aqui a fórmula ensaiada, primeiramente, no reino e, depois, experimentada nas ilhas atlânticas" (NASCIMENTO, 1985, p. 11).

Rev. Direito Econ. Socioambiental, Curitiba, v. 2, n. 2, p. 401-437, jul./dez. 2011 
As primeiras sesmarias nas terras brasileiras se formaram por meio dos forais e das cartas de doação com o compromisso de promover as primeiras diretrizes fundiárias quanto ao povoamento e à exploração em troca da concessão de grandes propriedades e dos privilégios e direitos aos donatários. Parecia, portanto, ser a melhor solução que o governo poderia dar à colônia a respeito do problema da organização político-administrativa. Assim, o monarca português evitava a aplicação dos recursos da coroa e incentivava os investimentos dos particulares, transferindo os riscos do empreendimento para os donatários e instaurando o início da tradição latifundiária brasileira (TEIXEIRA, 2000). Contudo, a política de povoamento não deu certo, com exceção das sesmarias de Pernambuco e São Vicente, onde a agricultura promoveu um pequeno interesse dos colonos em povoar essas áreas; as demais capitanias tiveram um desenvolvimento crítico, com total estagnação e abandono - algumas das sesmarias sequer foram aproveitadas e cultivadas por seus donatários (REIS, 2000). ${ }^{3}$

A delegação de poderes e direitos a um pequeno grupo de confiança do rei deu início ao que se denominou de "mandonismo local", subsistindo as autoridades governamentais ausentes ou distantes, levando ao enfraquecimento da esfera pública na sociedade e estabelecendo o poder privado, destacadamente na área rural. O entrelaçamento entre o poder público da metrópole e os agentes privados encarregados de cumprir as Ordenações Afonsinas na colônia fez com que o Estado fosse visto como aqueles indivíduos que representavam a esfera pública ordenada.

A ausência de operatividade das sesmarias, em grande parte determinada pelas normas em vigor, gerou a cultura dos grandes latifúndios por causa dos costumes portugueses de exploração de grandes áreas de

3 Nestor Goulart Reis considera que a "política urbanizadora deve ser entendida como um esforço para controlar as transformações que ocorrem num processo de urbanização. [...] No caso brasileiro, em decorrência do regime colonial, Portugal se colocava na origem das transformações do sistema social, como agente da política de colonização e, como parte importante desta, da política de urbanização. [...] Nas capitanias pertencentes à Coroa, cabiam exclusivamente a essa as tarefas de urbanização, reservando-se ao rei e aos atos relativos à criação ou à elevação dos povoados à condição de vilas e cidades".

Rev. Direito Econ. Socioambiental, Curitiba, v. 2, n. 2, p. 401-437, jul./dez. 2011 
terra. Depois de perder o caráter administrativo que lhe fora infundido pelos legisladores de Portugal para acentuar seu conteúdo dominical, o regime de sesmarias gerou, ao contrário de seus propósitos iniciais, a grande propriedade (NASCIMENTO, 1985).

Com a incorporação das terras sesmariais à propriedade privada, já na fase imperial, formaram-se novos modos de aquisição do solo, sendo positivados pela Lei n. 601 de 18 de setembro de 1850, conhecida como Lei de Terras, entre eles o regime de posse, o usucapião e o negócio jurídico.

\section{A Lei de Terras - o novo paradigma fundiário no Brasil colonial}

A concessão do solo, até a proclamação da independência brasileira, dava-se por meio da transferência do domínio da propriedade para um particular por meio do sistema de sesmarias. Após 1822, um novo modo de aquisição foi previsto pelo ordenamento fundiário, a ocupação de terras por meio do regime possessório, além das formas já previstas. Contudo, a posse recaía sobre a coisa e não sobre a titularidade do direito de propriedade, sendo uma mera situação de fato, apesar de às vezes constituir a moradia e a cultura daquele que efetivamente possuía o bem. Com o advento da Lei n. 601/1850, as terras devolutas, aquelas de domínio público que não eram utilizadas pelo Estado (NASCIMENTO, 1985), eram objetos da posse. Com o regime instituído pela Lei de Terras, acabava a situação fática do sistema possessório ilegítimo no Brasil.

A aquisição do território brasileiro pelo Império português se deu por título originário de posse. A coroa, por meio de doações realizadas pelo sistema sesmarial, iniciou a transferência das terras do domínio público para o privado, fazendo-se necessário, para a garantia das relações, os registros tanto do domínio público quanto das posses. Esses registros eram realizados nas paróquias católicas, sendo conhecidos como "registros do vigário". Com o decorrer dos anos, o registro, que era inicialmente feito pela Igreja, passou a ser monopólio do Estado. $\mathrm{Na}$ atualidade, o registro público é realizado por oficiais registradores, e a 
partir de 1988 a natureza dessas serventias extrajudiciais passou a ser de caráter privado.

O artigo $5^{\circ}$ da Lei n. 601/1850 fazia a previsão de que toda posse mansa e pacífica que fosse adquirida por intermédio de ocupação primária ou ainda aquela cultivada pelo primeiro ocupante, para o cultivo ou a moradia habitual do posseiro ou de seu representante, configurava a transferência do domínio. $\mathrm{O}$ artigo $8^{\circ}$ do referido diploma fundiário exigia, com requisitos objetivos de qualificação da posse, a utilização potencial e o aproveitamento da terra (MACEDO, 1939).

O sistema de posse é resultado da legitimação da terra por meio da morada habitual e da cultura efetiva, prevendo a Lei de Terras um lapso temporal para legitimar os requisitos exigidos por lei; o descumprimento do tempo de carência pelo posseiro leva à perda do direito de adquirir a propriedade. Encontrava-se previsto no artigo $5^{\circ}$ do Decreto-lei n. 9.760/46, no qual dispunha em sua alínea "a" a incorporação do domínio particular por meio da posse, conforme já indicava a Lei n. 601/1850.

Posteriormente, a Lei federal n. 4.504/1964 (BRASIL, 1964), denominada de Estatuto da Terra, previa em seu artigo 97 o regime possessório dos ocupantes de terras públicas federais, legitimando a posse e a preferência para a aquisição até a faixa de 100 hectares, tornando a terra produtiva por meio de seu trabalho ou de sua família. Estabeleceu-se na lei agrária a aquisição dominical onerosa ou pelo fato da posse, conforme a Lei n. 6.383/76 (BRASIL, 1976), em seu artigo 29, parágrafo $1^{\circ}$.

A Lei de Terras, ao fazer a previsão do sistema possessório, não se referiu ao modo de aquisição pelo decurso do tempo, mas tratou da posse-produção, vinculando-a à morada habitual e à cultura efetiva. $\mathrm{O}$ artigo $1^{\circ}$ do referido diploma de terras previa a aquisição de terras devolutas por meio oneroso, proibindo a transferência do domínio por outros títulos, concluindo-se que o regime de posse e a usucapião não eram institutos passíveis de transferir a titularidade da propriedade devoluta. As terras devolutas, compreendidas como as terras que pertencem "[...] ao domínio público de qualquer das entidades estatais, não se acham utilizadas pelo Poder Público, nem destinadas a fins administrativos específicos. 
São bens públicos patrimoniais ainda não utilizados pelos respectivos proprietários" (MEIRELLES, 1996, p. 463).

A Lei de Terras, em seu artigo $2^{\circ}$, regulava o despejo como forma de punição para aqueles que possuíssem como sua a propriedade devoluta. Nesse sentido, o egrégio Tribunal Constitucional editou a Súmula n. 340, entendendo que, desde "a vigência do Código Civil, os bens dominicais, bem como os demais bens públicos, não podem ser adquiridos por usucapião" (BRASIL, 1963). A doutrina majoritária, ao comentar a referida súmula, entendia que o mecanismo para aquisição da propriedade de terras de domínio público poderia ser a ação de usucapião e o regime de posse, durante fase do período imperial até a promulgação e vigência do diploma civilístico de 1916. Aos bens de domínio público antes da vigência do Código Civil era admitida a ação de "usucapião dos referidos bens, exigindo-se tão somente que a posse do prescribente se prolongasse por quarenta anos" (MONTEIRO, 1966, p. 127). Portanto, após a vigência do Código Civil, as terras de domínio público se tornaram foram usucapidas (NASCIMENTO, 1985, p. 16).

Nessa esteira, o artigo 148 da Constituição de 1937 regulava a inadmissibilidade da prescrição aquisitiva contra os bens públicos, ressalvando que aquela usucapião denominada pro labore, regulada pela Lei n. 6.969, de 10 de dezembro de 1981, em seu artigo $2^{\circ}$, era preceituada como a usucapião especial estendida "às terras particulares e às terras devolutas" (BRASIL, 1981).

O regime de posse foi o segundo instrumento para a aquisição dos bens imóveis. Inicialmente, a posse era um simples fato, sem a possibilidade da concessão do solo desde que fosse destinada à morada habitual e ao cultivo efetivo. Com a vigência da Lei n. 601/1850, o lapso temporal anterior foi legitimado pela norma jurídica, concedendo a titularidade àqueles que já possuíam terras públicas como suas e tivessem cumprido os requisitos previstos. A Lei de Terras, quanto às aquisições futuras, aboliu o regime de posse.

A usucapião foi a terceira forma de transferência da propriedade para o particular por meio da posse prolongada no tempo, sendo admitida antes da codificação civil de 1916. 
Por fim, a quarta modalidade admitida na fase colonial até o início do século XX era a aquisição por meio do negócio jurídico, transferindo as terras devolutas por meio do contrato solene de compra e venda e, posteriormente, por intermédio da concorrência pública, mediante a autorização do ente da federação.

\section{A questão fundiária na ordem civil brasileira}

Diante da nova ordem político-social instaurada após a Independência brasileira, dois fatores devem ser observados pelo governo brasileiro quanto à questão fundiária. Em primeiro lugar, o problema da demarcação e da medição das sesmarias que foram concedidas aleatoriamente sem confirmação. Em decorrência da concessão sesmarial, as terras em comisso que perderam a eficácia da doação passaram a ser bens públicos por causa da carência dos requisitos constitutivos para a efetivação da concessão, não sendo, portanto, incorporadas ao domínio particular. A segunda questão apontada a ser solucionada seria das terras que não foram concedidas pelo regime das sesmarias e que eram possuídas por terceiros.

As terras sem demarcação e medição que foram concedidas aos particulares tiveram como causa a carência de agrimensores no Brasil, não sendo possível responsabilizar o concedente por esse fato. Diversos motivos impediram a confirmação das concessões realizadas pelo monarca, tais como a dificuldade de comunicação decorrente da precariedade dos recursos utilizados na época e da imensidão de terras que deveriam ser percorridas para se homologar tais concessões. Vislumbrando os impedimentos para a ratificação das concessões das áreas dadas em sesmarias, a Lei n. 601/1850 revalidou os títulos concedidos, incorporando as propriedades ao domínio dos particulares beneficiados.

O direito de propriedade previsto no artigo 524 no diploma civil de 1916 tratava das faculdades de usar, gozar e dispor de seus bens, prevendo a possibilidade de exercer o poder de reavê-los de quem quer 
que os possua injustamente. O legislador ordinário considera hipóteses de limitações ao direito de propriedade, destacadamente, o direito de vizinhança, artigo 554 e seguintes do Código Civil, e também as determinadas pelas posturas municipais ou regulamentos administrativos, artigo 572 in fine do mesmo diploma.

O atual contorno do direito de propriedade previsto na legislação civil e urbanística coaduna-se com as regras jurídicas estabelecidas pela Constituição Federal de 1988 (BRASIL, 1988) ao fixar o regime de liberdade para a construção de uma sociedade livre e igualitária, nos termos do artigo $3^{\circ}$ e incisos da Carta Magna de 1988, relativizando o sagrado e absoluto direito de propriedade, que deverá atender a sua função social, prevista no inciso XXIII do artigo $5^{\circ}$ da Constituição da República, sendo reafirmado nos princípios gerais da atividade econômica, contidos no artigo 170, inciso III; e, ainda, no capítulo da política urbana, artigo 180 e seguintes da Constituição. Estabeleceu, ainda, a Constituinte sobre a política agrícola e fundiária e da reforma agrária no artigo 184 da Carta Maior de 1988.

As diretrizes traçadas pelo legislador constitucional a respeito de alguns institutos jurídicos foram determinadas com objetivo de obter a regulação fundiária. Entre eles se destacam a desapropriação urbana e a usucapião individual e coletiva.

A desapropriação prevista no artigo 182 , parágrafo $3^{\circ}$, da Constituição (BRASIL, 1988) estabelece o pagamento prévio e justo de indenização em dinheiro, ressarcindo o administrado pela retirada do bem imóvel que lhe pertencia, mas destinando aquele bem ao interesse social. Além da expropriação social, existem outras formas de intervenção assemelhadas à desapropriação, que buscam atender a função social da propriedade antes de chegar ao ato expropriatório. Para se evitarem abusos de direitos, a Constituinte impôs limitações ao poder expropriatório contidas no artigo 185, consistindo em verdadeiras causas objetivas que impedem o ato de desapropriar o particular, como no caso da pequena e média propriedade rural definida em lei, desde que seu proprietário não possua outra, bem como a propriedade produtiva, conforme dispõe o artigo 185, incisos I e II, da Constituição Federal de 1988. 
Além das limitações constitucionais ao direito de propriedade, existem aquelas previstas pelo uso das posturas municipais ou dos regulamentos administrativos. Hipótese diametralmente oposta é a de contratos de cessão de uso entre o Poder Público e o particular para a utilização, gratuita ou onerosa, de bens de domínio público. Portanto, o particular não terá direito a indenização, pois usa o que é de domínio do Estado. Já na hipótese de limitação administrativa, essa natureza lhe retira o caráter indenizatório. ${ }^{4}$

A intervenção do Estado na propriedade privada tem a finalidade de expropriá-la, sendo precedida de justa e prévia indenização em dinheiro, como regra, sendo admitidas exceções. O comum nos casos de desapropriação é que o Estado, após obter a posse do bem, protele o pagamento da indenização de todas as formas, usando o Poder Judiciário, moroso em suas decisões e passando o dever do pagamento à administração subsequente. Dessa forma, não nos parece que vigore mais o preceito do artigo 15 do Decreto-lei 3.365/41 (BRASIL, 1941), que possibilitava ao expropriante, mediante alegação de urgência, depositar o preço estimado conforme o parágrafo $1^{\circ}$, alíneas "a", "b", "c" e "d" do referido diploma legal.

A indenização é uma exigência imposta por lei para garantir o equilíbrio entre o interesse social e o individual; "a expropriação vem a resolver por meio de uma conversão de valores patrimoniais: no patrimônio onde estavam os imóveis, a entidade expropriante põe o seu valor pecuniário", considerando ainda que a "garantia principal da justiça da indenização está na possibilidade de, em caso de desacordo, o expropriado poder recorrer aos tribunais judiciais para discutir o montante" (LIMA apud NASCIMENTO, 1985, p. 7).

Reforça esse entendimento a disposição final contida na Constituição, que exclui a necessidade da justa e prévia indenização em

4 Conforme a Súmula 142, também do extinto TFR: "a limitação administrativa non aedificandi imposta aos terrenos marginais das estradas de rodagens, em zona rural, não afeta o domínio do proprietário, nem obriga a qualquer indenização" (BRASIL, 1983). 
dinheiro apenas nos casos ressalvados na própria lei maior. Desse modo, o direito de propriedade está inserido no Título II, como direito e garantia fundamental da pessoa, essência do regime democrático, que, ao estabelecer a segurança jurídica, foi expresso em seus fundamentos com os princípios da legalidade, inciso II; do devido processo legal, em seu inciso LIV; o do contraditório e o da ampla defesa, inciso LV, todos do artigo $5^{\circ}$ da Constituição Federal.

\section{A terra como meio de especulação do mercado imobiliário}

O processo de industrialização no Brasil chegou ao seu ponto culminante por meio da intensificação da atividade econômica nos períodos compreendidos entre anos de 1940 e de 1970, acarretando a expansão da ocupação de determinadas áreas da cidade. Observou-se o crescimento da concentração de riquezas, um fato inevitável, agravando o quadro de segregação, de desigualdades sociais e de marginalização dos grupos sociais desfavorecidos. Caracterizou-se, assim, durante essas décadas, o quadro de miséria e pobreza existente até os dias atuais no Rio de Janeiro (ARANTES, 2000). ${ }^{5}$

O quadro urbano a partir dos anos de 1970 é marcado pela aplicação de políticas que privilegiavam a lógica ditada pelos interesses dos grupos de empreendedores (ABRAMO, 2001, p. 162), consagrando como meta a acumulação de patrimônio, traçando, portanto, uma nova

5 [...] Duas gerações urbanísticas depois, o que poderia ter sido motivo de escândalo - a revelação da mercadorização integral de um valor de uso civilizatório como a cidade - tornou-se razão legitimadora ostensivamente invocada: aqui a novidade realmente espantosa, e tanto mais que eficiente, não só por deixar a crítica espontânea da cidade-empresa com a sensação de estar arrombando uma porta aberta, mas, sobretudo por contar com a "compreensão" das populações deprimidas por duas décadas de estagnação econômica e catástrofe urbana: fica assim bem mais simples persuadi-las a se tornarem "competitivas", na pessoa de suas camadas "dinâmicas" bem entendida. Esse o núcleo originário da "sensação coletiva de crise", sublimada pela nova ênfase na autoimagem dos habitantes, tal como Ihes é devolvida pela superfície refletora dos Grandes Projetos, neste final de século.

Rev. Direito Econ. Socioambiental, Curitiba, v. 2, n. 2, p. 401-437, jul./dez. 2011 
dinâmica de ocupação. O resultado foi o agravamento do cenário urbano e a composição do perfil dual em que os ricos ocupam as áreas nobres da cidade e utilizam os investimentos públicos em infraestrutura e em serviços básicos que deveriam estar presentes, deixando as áreas remanescentes para o uso da população menos favorecidas (PÓLIS, 1997). ${ }^{6}$

\section{As novas atividades econômicas e a dinâmica imobiliária na cidade do Rio de Janeiro}

A vocação do Rio de Janeiro para o setor de serviços pode ser verificada em um momento em que a economia sofreu um colapso nas atividades industriais. Aquele novo setor, nos anos de 1970, representava a ocupação de $56 \%$ de toda a mão de obra ativa da capital e das áreas sobre a sua influência. Tal fenômeno vinha se acentuando a partir da década de 1960, quando pouco mais da metade de toda a força de trabalho pertencia ao setor industrial, reduzindo essa participação na década seguinte para 44\%, caindo mais dois pontos percentuais nos anos de 1980 .

Os trabalhadores passaram a desenvolver suas novas tarefas e também a adquirir produtos e serviços fora dos seus municípios de origem, transformados em verdadeiras "cidades dormitórios", sem um setor de comércio ou serviço pujante (LAGO, 2000). Apesar dos esforços de integração da antiga Guanabara com o Rio de Janeiro, verificou-se o incremento da atividade produtiva naquela, merecendo destaque as cidades de Niterói e de Duque de Caxias como polos de atração de mão de obra, restando aos municípios vizinhos a oferta de vagas informais como resultado

6 O valor da terra/propriedade urbana é determinado pelo mercado formal em razão de diversos fatores tais como o processo de especulação imobiliária, localização física e territorial, potencial de uso e de construção, oferta de serviços e equipamentos públicos, potencial de uso da infraestrutura urbana, capacidade da rede viária, oferta e qualidade do transporte. [...] A formação de assentamentos precários para fins de moradia, tem sido a alternativa permanente desta população, padrões baixos de qualidade de vida. A desigualdade e injustiça estão presentes pela não participação na distribuição da renda e riqueza da cidade e pelas precárias condições de vida.

Rev. Direito Econ. Socioambiental, Curitiba, v. 2, n. 2, p. 401-437, jul./dez. 2011 
da eleição de um modelo concentrador para a economia do Estado. Niterói, capital estadual até 1974, era a terceira área de atração de mão de obra metropolitana em 1980, desenvolvendo atividades no setor de comércio e serviços públicos e privados, com destaque para a indústria naval.

O crescimento do setor industrial, destacando-se Niterói, destoando essa característica da economia no caso do Rio de Janeiro, acentuou a desconcentração das atividades. Contudo, o setor de serviços teve um grande crescimento no caso daquele município (LAGO, 2000). A realidade demonstra uma ocupação seletiva das cidades periféricas da metrópole por estabelecimentos, principalmente nas atividades de alimentação e alojamento, desse modo estabelecendo um processo de urbanização crescente nas áreas limítrofes ao grande centro. Prova disso é que, na década de 1980, na capital, mais da metade dos empregados no setor terciário pertenciam à categoria dos auxiliares nos mais variados tipos de serviços ofertados, onde são encontrados os setores dinâmicos e avançados da economia formal. Por outro lado, coube às cidades periféricas a ocupação de sua mão de obra no setor de produção de alimentos, de acordo com os dados colhidos pelo censo econômico de 1980 (ARANTES, 2000).

Pode ser observado no Rio de Janeiro que a remuneração das atividades de serviços apresenta a maior distância entre os salários médios pagos do que aqueles praticados nas cidades periféricas, ou seja, o salário médio na periferia correspondia a $43 \%$ do salário médio da área central.

O processo econômico na cidade do Rio de Janeiro, no período dos anos de 1970, baseou-se na produção de moradias. O setor da construção civil já vinha obtendo um crescimento a partir da década de 1960, em grande parte atribuído à política desenvolvida pelo Sistema Financeiro de Habitação (SFH). Desde então, passou a circular uma grande soma de capital financeiro, gerando os necessários recursos para o insipiente mercado imobiliário, sendo necessário refletir sobre as cruéis consequências que o mercado estabeleceu. ${ }^{7}$

7 Cardoso (1996, p. 98-99) adverte que a oferta de terras e a de crédito condicionam e direcionam o mercado. Assim, o "fim do Sistema Financeiro de Habitação gerou não apenas a crise e a redução 
Observa-se que a contradição está no "valor de uso que o lugar representa para seus habitantes e o valor da troca com que ele se apresenta para aqueles interessados em extrair dele um benefício econômico qualquer [...]" (ARANTES, 2000, p. 26). Dessa forma, criaram-se rentáveis alternativas para o capital ser remunerado de maneira atrativa (PÓLIS, 1997).

Ocorreram, na verdade, importantes ingressos de recursos do setor financeiro para a área destinada a atender a demanda represada por moradia pelos assalariados. Essa tarefa foi desenvolvida pela atuação de grandes oligopólios de incorporadoras que, somadas às participações das pequenas e médias empresas, responsáveis pela construção dos chamados "conjuntos habitacionais", repartiam o cenário com empreiteiros individuais. Cabe lembrar que os excluídos do acesso ao crédito do $\mathrm{SFH}$ utilizavam-se da autoconstrução, inclusive na modalidade cooperada, conhecida por "mutirão".

Inicialmente, as grandes incorporadoras realizaram maciços investimentos adquirindo áreas localizadas em setores da cidade reconhecidamente valorizados, como nos casos da Tijuca, Botafogo, Ipanema, Leblon e Barra da Tijuca. Tais operações destinaram-se à construção de edifícios de apartamentos voltados para as classes sociais mais favorecidas que poderiam pagar o preço majorado. Esgotado esse modelo pela ausência de oferta ou pela sua existência, mas com preços que inviabilizaram o seu repasse aos moradores, retomaram-se, assim, as atenções para aquelas áreas até então preteridas, realizando obras de padrões elevados na qualidade, com valores finais atrativos para as classes trabalhadoras. Obtiveram-se elevados ganhos em razão da enorme quantidade de operações idênticas realizadas.

O setor imobiliário foi incentivado a expandir sua atuação para outras áreas da capital por meio de investimentos na sua infraestrutura realizados com verbas públicas (CARDOSO, 1996, p. 98):

da oferta global, mas a sua concentração em segmentos de mais alta renda, com maior capacidade de poupança, e que passam a se configurar como demanda solvável para o setor. A expansão se dá naquelas áreas que combinem a oferta de terras urbanizadas com a legislação suficientemente permissiva para viabilizar economicamente os empreendimentos". 
quanto à dinâmica imobiliária, conclui-se que a oferta de moradias se faz pela ação de vários tipos de agentes e de várias formas de produção. O setor empresarial foi responsável por cerca de $50 \%$ da oferta total na última década, tendo esse percentual se reduzido à metade nos últimos anos. Coexistindo com a forma empresarial, identificou-se a produção estatal, ou cooperativada, a autoconstrução e as formas mercantis informais. A produção empresarial tende a atuar basicamente nas regiões onde se concentra a população de maior poder aquisitivo, enquanto que as outras formas se distribuem pelos demais segmentos do mercado. Uma política global para o redirecionamento do mercado de moradias não pode, pois, concentrar-se apenas nas questões relativas ao segmento empresarial.

Podendo o mesmo fenômeno ser identificado pela construção da ponte ligando o Rio de Janeiro a Niterói (LAGO, 2000). ${ }^{8}$

Em relação ao modelo de produção imobiliária de pequeno porte, houve um dinamismo acentuado nas regiões do subúrbio carioca, resultante da estrutura residencial destinada às classes média ou média baixa. Contudo, o modelo familiar de ocupação segue um perfil destinado a atender as necessidades de acesso aos meios de consumo e do próprio solo dessas categorias sociais, ou seja, "o critério de decisão familiar de localização dos seus domicílios é formulado a partir da escolha (trade off) entre o consumo de 'acessibilidade' [...] e o consumo de quantidade do solo urbano" (ABRAMO, 2001, p. 161). O que levou aos micros incorporadores a investirem em um padrão multifamiliar, por meio de construções

8 Luciana Lago (2000, p. 89) conclui que também nesse período, "a Barra da Tijuca tomou-se a nova fronteira aberta à expansão do grande capital imobiliário, possibilitando ganhos de inovação e de urbanização significativos. Cabe lembrar que o boom imobiliário na Barra só foi possível graças à atuação do poder público, que, através das políticas de investimentos, especialmente abertura de vias e estradas, e da legislação urbana, garantiu as condições necessárias à acumulação. O mesmo pode ser dito em relação ao dinamismo do mercado imobiliário empresarial em Niterói nos anos 70. A construção da ponte Rio-Niterói em 1974 intensificou os fluxos tanto populacionais quanto de capitais entre as duas cidades, provocando um intenso processo de verticalização, principalmente na Zona Sul de Niterói, e a ocupação da área de expansão do município, ou seja, a região oceânica onde está localizado o distrito de Itaipu". 
edilícias de pequeno porte, adequados às rendas dos futuros proprietários (SILVA, 1981).

Já no final dos anos de 1970, remanesceu a figura de alguns bairros localizados nas áreas mais afastadas do subúrbio do Rio de Janeiro, como no caso do Méier e Penha. Na segunda metade da década de 1970, os investimentos realizados no setor financeiro geraram o crescimento do limite de financiamento, redirecionando o mercado para aplicar recursos em áreas de valorização intermediárias, como no caso da Zona Norte e da área suburbana do Rio de Janeiro. O projeto elaborado pelo mercado imobiliário atuou como uma "mão invisível urbana" (ABRAMO, 2001, p. 161), reestruturando o modelo de valorização do solo urbano (ARANTES, 2000), participando na "transformação do uso do solo na cidade e mesmo na metrópole, por outro, sua participação quanto à quantidade de unidades produzidas em relação ao volume global de novos domicílios foi relativamente pequena" (LAGO, 2000, p. 89).

Apesar dos programas existentes na Companhia Estadual de Habitação (Cehab) e dos recursos disponíveis por meio do SFH, a população classificada como de baixo padrão aquisitivo adotou a modalidade de acesso à casa própria conhecida como "autoprodução". Os terrenos ocupados para essas construções resultaram de compras de lotes ou mesmo de ocupações irregulares. Prova disso é que, entre os anos de 1965 a 1982, na cidade do Rio de Janeiro foram construídas em torno de 60 e 2 mil unidades em conjuntos habitacionais que atenderam apenas a uma pequena parcela da população, justamente aqueles com renda equivalente a cinco salários mínimos, e as cooperativas habitacionais criaram oportunidades para a construção de 52 mil apartamentos para àqueles em que a renda era o dobro dos primeiros contemplados por verbas públicas.

O modelo do SFH, utilizando os recursos do Fundo de Garantia por Tempo de Serviço (FGTS), baseava-se no retorno do investimento para gerar novos financiamentos. Dessa forma, em 1980, foi possível constatar que os recursos não contemplavam um contingente de aproximadamente 300 mil famílias, com rendimentos inferiores a dois salários mínimos. A região da cidade disponível para a aplicação das verbas 
referidas era a Zona Oeste, com atuação destacada das cooperativas no bairro de Jacarepaguá (CLADERA apud LAGO, 2000).

O sucesso da autoprodução de moradia se deve a alguns fatores determinantes, como a ocupação irregular do solo, fato que barateou o acesso à casa própria. Outro elemento favorável para o êxito da autoconstrução foi a tentativa frustrada das autoridades públicas de impedir o processo de favelização, o qual teve seu início no século passado, na década de 1970. Houve um redimensionamento desses assentamentos para outras áreas onde a prática foi tolerada, gerando o crescimento daquela população nos subúrbios e na Zona Norte. O derradeiro fator de incremento da autoconstrução foi à remoção das populações faveladas da Zona Sul da cidade para as novas áreas já citadas.

A principal característica da ocupação da Zona Oeste foi a oferta de lotes populares em abundância e com baixos investimentos em infraestrutura e pagamento ao longo prazo, além da iniciativa dos trabalhadores de baixa renda de construírem a casa própria, tornando esse padrão de aquisição de moradia motivo para a manutenção da baixa remuneração necessária para a sobrevivência desses trabalhadores.

A ocupação da Zona Oeste, a partir dos anos de 1950, ocorreu por meio da produção extensiva de loteamentos populares. No final da década de 1970, a forma predominante de acesso a terra na área menos valorizada da cidade era a compra do lote e não a ocupação. Em 1980, a população favelada situada nessa região representava menos de $10 \%$ das moradias.

O sistema de loteamentos adotado não foi aquele criado de maneira ortodoxa pelo legislador, mas o que as contingências da realidade precária permitiram adaptar na sua implantação. Compreendiam as etapas de aquisição parcelada da área pelo loteador individual ou coletivo ou até mesmo valendo-se da ocupação irregular. Com a posterior abertura de ruas, iniciavam-se as vendas dos primeiros lotes a prazo com preço fixo e pagamento em até 60 meses, por meio de contratos particulares. Em seguida, colocava-se o meio-fio, realizando-se a drenagem do terreno a ser construído, por meio do uso dos valores obtidos com a venda dos 
primeiros terrenos. Nessa etapa, havia a primeira tentativa de regularização com a aprovação do projeto de loteamento, prosseguindo-se as vendas independentemente do "aceite" pela Administração Pública municipal.

A ocupação demográfica espacial consolidou-se por meio de uma estrutura socioespacial marcada pela desigualdade nas formas de produção do espaço metropolitano, acentuando um mercado imobiliário na década de 1970, com demasiada oferta de apartamentos para a classe média nas áreas nobres da cidade, gerando, como contrapartida, a favelização dos subúrbios e das encostas de morro da Zona Sul e a crescente oferta de lotes populares na periferia (ABRAMO, 1996).

Assim, a depreciação residencial gera uma mobilidade do fluxo de moradores dessas áreas, criando uma "destruição criativa de externalidades de vizinhança”. Portanto, a proposição de uma convenção urbana possui como objetivo a modificação da vizinhança de certa localização onde se estrutura uma dinâmica residencial urbana (SMOLKA; AMBORSKI, 2000).

\section{A mobilidade residencial e os fluxos migratórios no Rio de Janeiro na década de 1970}

Na década de 1970, observou-se que houve um movimento migratório da Região Sudeste em direção ao Centro-Oeste. Para o Sudeste veio a população das regiões Nordeste e Sul, apresentando os Estados de São Paulo e Rio de Janeiro uma intensa movimentação populacional intraestadual, especialmente em suas respectivas regiões metropolitanas (LAGO, 2000).

Em 1980, a periferia em consolidação abrigava mais que o dobro da população migrante das demais periferias, apresentando $22 \%$ do total de residentes da macroárea e $71 \%$ do crescimento observado na mesma macroárea. A Zona Sul da capital apresentou um contingente de migrantes, bastante elevado, pouco mais de $16 \%$ da população, e a periferia mais distante do Centro, classificada como "em expansão", apresentou 
números semelhantes de migrantes ainda nos anos de 1980. No primeiro caso, foi resultado da migração populacional, enquanto no segundo houve um aumento da taxa de natalidade.

A Zona Oeste da cidade apresenta, ao contrário das demais áreas periféricas, a migração intermunicipal aumentando o crescimento populacional por meio dos deslocamentos das áreas centrais e da Zona Sul para localizarem no interior da cidade. O Subúrbio 2 e a Zona Oeste apresentaram as maiores taxas de mobilidade intramunicipal - em torno de 54\% (LAGO, 2000).

Os principais distritos receptores de migrantes na periferia e as áreas mais centrais da capital, compostas pelas Regiões Administrativas (RAs) de Copacabana, de Botafogo e da Lagoa, apresentaram os maiores contingentes de migrantes - entre 44 mil e 51 mil. Ao mesmo tempo, foram áreas de atração e expulsão populacional; cabe salientar que Copacabana teve um crescimento negativo. Botafogo e Copacabana apareciam em 1970 como as duas RAs com maior fluxo de migrantes na década, e a Região Administrativa da Lagoa, onde se localiza a favela da Rocinha, ocupava o sexto lugar entre as áreas da capital com maior fluxo.

A dinâmica migratória exige um estudo sobre a origem e o destino dos fluxos. Na década de 1970, a grande maioria dos migrantes que se encaminharam para a capital tinha como origem outros Estados da Federação, e a outra metade da população migratória, oriunda de municípios do interior ou da própria metrópole, para um dos municípios da região metropolitana, deslocando-se dentro do próprio Estado e dirigindo-se predominantemente para a periferia.

Diferentes regiões forneceram mão de obra para a cidade do Rio de Janeiro, como o Nordeste com $44 \%$ dos migrantes que chegaram à cidade nos anos de 1970; dos Estados do Sudeste, o percentual correspondeu a $23 \%$, e $18 \%$ era originários das demais regiões do país. Pouco mais de $3 \%$ dos migrantes para a cidade do Rio de Janeiro vinha do interior do próprio Estado, sendo que $10 \%$ era oriundos de outros municípios da própria metrópole, o que era pouco significativo no universo da população migratória. 
Na Zona Sul, além das favelas, a concentração de novos empreendimentos imobiliários com alta demanda de mão de obra desqualificada pode explicar o grande contingente de migrantes vindos do campo. O reflexo dessa taxa de concentração elevada é descrita como um "tecido urbano" (PRETECEILLE; VALADARES, 2000).

A metrópole do Rio de Janeiro aparece receptora de fluxos migratórios, com deslocamentos populacionais intrametropolitanos ocorridos na década de 1970: um conjunto de fluxos para a capital, nas três áreas periféricas, e um conjunto de fluxos de pequena distância, especialmente entre áreas contíguas, dentro da própria periferia. O primeiro padrão de deslocamento correspondeu a mais de $51 \%$, e o segundo aproximadamente $25 \%$. É fácil perceber que as altas taxas de crescimento demográfico dos municípios periféricos foram sustentadas pelos deslocamentos intrametropolitanos.

Nos anos de 1970, a periferia metropolitana do Rio de Janeiro foi a principal área receptora de migrantes na década, vindos majoritariamente da capital e, em menor escala, da própria periferia. Os deslocamentos para a Zona Sul da capital caracterizaram uma outra tendência migratória da década. O local de origem desses migrantes era especialmente do Nordeste, e um quarto destes, da zona rural, eram camponeses ou trabalhadores urbanos pobres que foram se estabelecer nas favelas da área.

É oportuno observar que, desde os anos de 1960, boa parte dos migrantes que se dirigiram para a Região Metropolitana do Rio de Janeiro na década de 1970 não foi diretamente para a periferia, e sim para as áreas centrais do município. Esse fenômeno é importante para se entender a segregação social do espaço metropolitano. Já nos anos de 1960, estudos demonstravam que a distribuição espacial na metrópole do Rio de Janeiro, segundo os dados censitários, era resultado de movimentos migratórios que se dirigiram para a capital e tinha como origem outras regiões do país, em particular o Nordeste, enquanto para a periferia haviam se deslocado basicamente populações da capital ou do interior do próprio Estado. 


\section{As alterações da dinâmica urbana: o perfil da década de 1980}

A migração diferencial ou seletiva pode ser observada na população que mudou de município de residência no interior da metrópole durante a década de 1970. Segundo os autores, ela apresentava um perfil socioeconômico ${ }^{9}$ de mais pobreza e menos instrução por ser mais jovem que a população metropolitana como um todo, vivendo em condições habitacionais também mais precárias.

O perfil dos migrantes que se deslocaram para as áreas periféricas caracterizava-se pela alta proporção de pessoas com rendimento entre dois e cinco salários, entre $38 \%$ e $46 \%$. Os que recebiam mais de dez salários eram compostos entre $4 \%$ e $7 \%$. Por aqueles com renda abaixo de um salário, representando $13 \%$ a $19 \%$, de tal forma que mais de $75 \%$ dos migrantes intrametropolitanos no período de 1970 até 1980 tinham renda familiar até cinco salários mínimos.

Os migrantes instalados nos subúrbios e centro da capital tinham o mais alto percentual de pessoas com rendimento inferior a um salário, entre $21 \%$ a $24 \%$, e também uma elevada proporção dos que recebiam entre cinco e dez salários representava por volta de $20 \%$. Os migrantes com renda acima de dez salários alcançaram um percentual entre $10 \%$ e $16 \%$, em comparação com os relativos às áreas periféricas. O perfil de renda da população residente nas diferentes áreas metropolitanas era alterado, na medida em que os migrantes apresentaram um perfil bastante semelhante ao da população de suas respectivas áreas de destino.

Os migrantes que ocuparam as áreas periféricas da cidade possuíam baixo nível de rendimento familiar, não ultrapassando, para a grande maioria, o valor de cinco salários mínimos. Na Zona Sul da cidade, em virtude da ocupação nos assentamentos localizados nas áreas de favela,

9 O perfil socioeconômico e as condições de moradia do migrante referem-se, no presente trabalho, à sua situação após o deslocamento espacial. Ao definir a situação de rendimento ou de trabalho do migrante como fator condicionante desse deslocamento, considera-se, na realidade, a situação social anterior à mudança análoga à posterior. Ou seja, os dados não permitem avaliar a ocorrência de uma mobilidade ascendente ou descendente posterior ao deslocamento espacial. 
encontra-se uma polaridade com altos percentuais de indivíduos sem instrução que compunham as classes desfavorecidas dessa região, na sua maioria, migrantes, e outros, com grau superior, representando a classe social mais privilegiada. Nas regiões central e suburbana, a ocupação pelos migrantes se deu por meio de um perfil menos homogêneo em comparação àqueles que eram domiciliados nas periferias, tendo rendimento entre cinco a dez salários mínimos, não atingindo a faixa daqueles que ocupavam as áreas da Zona Sul da cidade.

Os deslocamentos intrametropolitanos na cidade do Rio de Janeiro estabelecem uma estrutura dinâmica nas áreas onde são ocupadas pelos migrantes que fixam uma inter-relação entre essas novas áreas ocupadas para traçarem um quadro socioeconômico bem variado, ou seja, a retirada da população carente, sem infraestrutura e com baixa instrução para regiões que indicam um perfil mais homogêneo no núcleo, principalmente nos bairros de Santa Cruz e Campo Grande, na Zona Oeste. Portanto, a heterogeneidade social da área central se deu em virtude dos deslocamentos regionais da população mais carente, fixando, na periferia, uma relação de homogeneidade social mediante os movimentos intrametropolitanos, para estabelecer essa relação de mobilidade.

A faixa etária é outro fator importante para traçar o quadro de mobilidade socioespacial percorrido pelos migrantes intrametropolitanos. Em 1980, a taxa de migração aproximava-se de $36 \%$ daqueles na faixa etária entre 25 e 44, percentuais que não eram encontrados em uma análise comparativa com a população metropolitana nessa mesma faixa etária, que apresentava um total de pouca mais de $28 \%$. Os migrantes com mais de 45 anos representavam um total de pouco mais de $13 \%$, enquanto os pontos apresentados da população da região metropolitana, nessa mesma faixa, perfaziam um total de $20 \%$. O perfil obtido a partir da comparação entre a faixa do fluxo migratório e a da população metropolitana revela que, na fase da infanto-juvenil entre 15 a 24 anos, os percentuais se mostram respectivamente idênticos: na primeira, em torno de $30 \%$; já na segunda, aproximadamente $20 \%$ das duas populações. 
A população migratória diferencia-se, portanto, daquela residente na área metropolitana, como visto, apenas na faixa etária entre os 25 e 44 anos. Esse quadro não foi encontrado em relação à comparação com os percentuais extraídos na Zona Oeste, variando o percentual entre $33 \%$ e $37 \%$ da população de migrantes, sendo elevados os números dessa categoria na faixa de até 14 anos nas regiões da Zona Oeste, periferia consolidada, periferia em consolidação e periferia em expansão, podendo ser concluído que a ocupação migratória nos anos de 1970 foi, basicamente, de famílias jovens com filhos nas primeiras fases da infância.

A Zona Sul e a área central apresentaram um perfil bastante diferenciado, com uma taxa crescente daquela categoria entre 15 e 24 anos, com percentuais entre $34 \%$ e $28 \%$, respectivamente, composta por jovens solteiros ou em fase de formação da família. Dessa forma, a ausência de empregos, a baixa renda e a insuficiente instrução dessa categoria acentuam o padrão de miséria e pobreza suportado pelos migrantes durante a ocupação dessas áreas, sendo precárias as condições socioeconômicas, instabilizando as condições básicas de moradia desses migrantes intrametropolitanos. As faixas entre 45 e 64 e acima de 65 anos não sofreram grandes variações nas áreas periféricas e da Zona Sul e Centro.

A Zona Sul da cidade apresentava um padrão de moradia diferente das áreas periféricas em razão do número de dormitórios ofertados à população de migrantes, diversificando a oferta de moradia. $\mathrm{Na}$ Zona Sul carioca, encontrava-se um percentual elevado dessa população morando em locais com três dormitórios ou mais, refletindo no padrão socioeconômico daqueles que ocupavam essa parte da cidade e modificando o perfil de investimentos realizados pelo mercado imobiliário em relação às áreas periféricas.

Outro indicador social da oferta de moradia é o tipo de residência construída para atender as populações nas áreas centrais, nos subúrbios, nas periferias e na Zona Sul da cidade. Nos anos de 1980, nessa última área, mais de $3 \backslash 4$ dos migrantes intrametropolitanos residia em edifícios de apartamento, ao passo que, nas regiões dos subúrbios 1 e 2, 
esse percentual variava entre $30 \%$ e $45 \%$, sendo um quadro bem diferente aquele vivido nas áreas periféricas, não ultrapassando a marca de $6 \%$.

Os anos de 1980, portanto, têm como característica a oferta de casas na periferia, revertendo um pouco o quadro em razão da ocupação de apartamentos realizada pelos migrantes. A modernização do sistema imobiliário foi resultado do processo de verticalização iniciado no final dos anos de 1970, produzindo como modelo de moradia a autoconstrução de casas para essa população com renda limitada. Portanto, o início da década de 1980 marca uma nova etapa na configuração do espaço urbano criado pelas regras ditadas pelo mercado imobiliário - é resultado direto da estabilidade no emprego, do nível de rendimento e da instrução da população que ocupava essas áreas.

O Rio de Janeiro, até o final dos anos de 1970, apresentou uma configuração espacial marcada pelo fenômeno da mobilidade intrametropolitano. Isso gerou um padrão de segregação socioespacial durante o período desenvolvimentalista da cidade, apresentando como principal perspectiva a exclusão da população desfavorecida, valorizando áreas na cidade onde os pobres localizavam-se em regiões que consolidavam a desigualdade no modo de organização socioespacial.

O processo de modernização enfrentado pelo mercado imobiliário pós-anos de 1980 consolidou a relativização do padrão dual de estrutura socioespacial, a partir da interação de pequenos e médios empreendedores que investiram nas áreas periféricas para adequar o novo segmento social - a classe média. O desenho urbano, já nos anos de 1970, teve um redimensionamento das regiões da periferia, isto é, tais áreas não seriam somente um local onde se instalava a pobreza e a miséria, apresentando condições de vida precárias, mas também um espaço de expansão do capital imobiliário e de capitação de recursos econômicos para valorizar certas áreas citadinas.

Por fim, o modelo de desigualdades sociais na cidade do Rio de Janeiro nos anos de 1980 revela um cenário de reestruturação socioespacial, fruto da influência do período desenvolvimentalista. 


\section{As tendências sociais e as influências na moradia pós-anos de 1980}

O ciclo final dos anos de 1970 apresenta um quadro crescente na economia, determinando grandes investimentos imobiliários, tanto por parte do Poder Público quanto pelos organismos da iniciativa privada, acentuando o estado de desigualdade social sentido na cidade após esse período. As expectativas no mercado de trabalho se revelaram inócuas. Apesar da ampliação de postos de qualificação média e alta representados por um número variado de pessoas, continuaram, ainda assim, as ocupações precárias adequadas aos baixos rendimentos percebidos pela maioria dos trabalhadores na década de 1980.

A Zona Sul apresenta como perfil um grau satisfatório de trabalhadores que cursaram os níveis médio e superior, diferenciando-se da área dos subúrbios, cujo contingente populacional desempenha suas funções no comércio, apresentando como grau de escolaridade, na sua maioria, pessoas que cursaram o ensino médio. Enquanto isso, nas periferias, o quadro apresentado é de profissionais ativos que exercem suas atividades no comércio e na prestação de serviços, representando em torno de $30 \%$ nesses segmentos. O domicílio dos trabalhadores que exercem atividades manuais na indústria e nos serviços é a principal característica para determinar a ocupação e a valorização de determinadas áreas na cidade.

Por meio da ocupação na cidade do Rio de Janeiro é possível estabelecer um perfil social da população ativa na década de 1980. No caso da Zona Sul, a característica distintiva das demais áreas seria a elevada diversidade sócio-ocupacional exercida pelos trabalhadores não manuais que apresentam nível médio de escolaridade, representando um número significativo nessa área. Adiciona-se uma elevada taxa de profissionais de nível superior, os trabalhadores do comércio e serviços, além dos trabalhadores da sobrevivência. Na área da Zona Sul apresentava-se, ainda, um panorama onde se desempenhavam ocupações precárias, necessitando essa população permanecer próxima à demanda por serviços. 
No caso da Barra da Tijuca, é interessante observar que essa área se tornou região limítrofe de expansão do grande capital imobiliário, diferenciando-se das demais áreas da localidade que se caracterizaram pelo elevado percentual de trabalhadores da indústria, principalmente, na construção civil.

O mesmo fenômeno não pode ser verificado na região dos subúrbios que apresentam como perfil um percentual menor de profissionais com nível superior, na sua grande maioria representados por trabalhadores que desempenhavam suas atividades no comércio e na prestação de serviços, além das funções industriais. Ainda nos anos de 1980, o quadro sócio-ocupacional traçado nas áreas periféricas era bem diferente daquele evidenciado na Zona Sul, principalmente na periferia em expansão que apresentava um perfil agrícola.

O grau de desigualdade social agrava-se quando se confrontam os perfis de renda nas áreas da cidade do Rio de Janeiro. Nos anos de 1970 a 1980, pode ser identificado um crescimento na concentração de renda nas áreas urbanas, acentuando o cenário de desigualdade fixado na região metropolitana fluminense.

Para se determinar as áreas de segregação espacial, deve ser estabelecido o vínculo entre a hierarquização da ocupação social exercida pelo trabalhador e o locus urbano em que está inserido, por meio de indicadores como renda familiar, acesso a terra e a serviços, entre outros. As informações quanto à reprodução social é resultado direto das regras contidas nas relações de trabalho que se modificam para dinamizar o mercado em certos períodos.

A heterogeneidade social pode ser verificada a partir do exame da faixa de renda da população da cidade do Rio de Janeiro, revelando que nas áreas centrais em relação às periféricas possui diferenças espaciais surpreendentes, apontando três fatos distintos: a) a Zona Sul obtendo rendas com um perfil heterogêneo; b) as periferias e sua divisão dual de rendas, com valores altos, pouco representando os limites estabelecidos; e c) o Centro e os subúrbios com um panorama estável, apresentando um perfil insignificante daquelas rendas nas faixas superior de 20 salários 
mínimos. O quadro de diferenças socioespaciais entre a Zona Sul até a periferia da cidade não apresenta diferenças na categoria de miseráveis da população; "o percentual de pessoas com renda familiar até um salário mínimo ficou entre 10,8\% e 14,8\%" (LAGO, 2000, p. 131).

Visando a reduzir o elevado contingente de miseráveis com faixa rendimentos de até um salário mínimo que ocupam a Zona Sul da cidade, durante duas décadas foram aplicadas políticas de controle e remoção de favelas nessa área considera nobre do Rio de Janeiro. O objetivo de implantar essas políticas de remoção foi facilitar a ação dos incorporadores imobiliários. Com a expansão imobiliária para a Barra da Tijuca, na década de 1970, garantindo a ocupação da parcela mais necessitada na Zona Sul em razão da redução dos interesses das grandes incorporados nessa área.

Em 1980, a ocupação da Zona Oeste localizava-se nas áreas limítrofes dessa localidade. Com a elevação do padrão de renda familiar nessa parte da periferia, houve um novo perfil de ocupação, a fixação dos trabalhadores estabelecendo um quadro socioespacial distintivo. Além da renda, outro fator que contribuiu para a ocupação da população ativa na cidade a partir de 1980 era o grau elementar de instrução, apesar de não estar relacionado diretamente à distribuição de bens e às condições materiais de reprodução, relaciona-se com esses fatores, principalmente o perfil de trabalho e de renda, sendo, portanto, o grau de instrução um condicionador da inserção e ascensão do trabalhador no processo determinado pelo mercado.

A estruturação socioespacial dos grandes centros urbanos é um conjunto de fatores ligados pela dinâmica político-econômica, determinando um padrão de desigualdades socioespaciais, em certas áreas as condições de vida são resultados diretos da instabilidade que o mercado imobiliário propicia no Rio de Janeiro, ou seja, as condições de acesso à terra e à moradia, aliados à disponibilidade de serviços urbanos colocados para a população citadina, leva-nos a estabelecer uma lógica cruel entre a dinâmica imobiliária destinada para as regiões nobres e a conexão entre o padrão de desigualdades observado diante da nova "requalificação urbana" (ARANTES, 2000). 
Diante do exposto, pode-se destacar como indicador da qualidade da habitação o tipo de residência fixada pela população da cidade. A modalidade de domicílio vertical coletivo, conhecida como "apartamento”, é resultado do processo de produção imobiliária empresarial, destinado, inicialmente, para a classe média capaz de suportar os valores de um padrão construtivo superior ao da construção por meio de casas. No Rio de Janeiro, na década de 1980, em torno de 41\% dos proprietários de apartamentos situava-se na Zona Sul por causa das primeiras iniciativas das atividades construtivas empresariais, pelas grandes e megas incorporadoras centradas nessa área. Enquanto isso, os subúrbios e a área central abrigavam aproximadamente $43 \%$ dos habitantes em apartamentos, investimentos aplicados pelos pequenos construtores coletivos ou individuais; o número de habitações na modalidade de casas na Zona Sul da cidade não era significativo, gerando em torno de $10 \%$, sendo essas construções situadas na maioria em favelas.

Os anos de 1970 inauguram a primeira renovação dos estoques residenciais dos subúrbios, por meio da substituição, em certas localidades, por moradias que antes eram de uso unifamiliar da edificação passando para o uso multifamiliar. A partir dessa renovação do padrão residencial, a forma adotada na década de 1980 foi à edificação de apartamentos, amplamente incentivada por maciços investimentos do setor empresarial imobiliário. Outro fenômeno observado nos subúrbios cariocas é a autoconstrução de casas em assentamentos irregulares, trazendo novos elementos diversificadores nesse perfil residencial nessa área.

A verticalização de residências apresentava pontos significativos na Zona Oeste carioca, destacadamente no bairro de Bangu, obtida essencialmente pela participação de atores como autoconstrutores, trabalhadores autônomos e pequenos incorporadores, quase sempre ilegais, geralmente produzindo moradias que eram acabadas pelos próprios proprietários. O subúrbio 1 e a região central, principalmente os bairros do Méier, Engenho Novo, Penha e Ilha do Governador, foram os primeiros a conhecerem o processo de verticalização, enquanto a área periférica ainda era caracterizada pela construção de casas. 
O perfil de construção pode ser mensurado, também, por meio do tamanho da habitação, obtendo-se como parâmetro o número de dormitórios encontrados em cada unidade. Na Zona Sul da cidade, ocupada, principalmente, por edifícios de apartamentos, o crescente processo de produção imobiliária realizada por grandes e megas incorporados acentuou a diversidade no estoque residencial ofertado. Nos anos de 1980, pouco mais de $30 \%$ dos imóveis ofertados possuíam dois dormitórios, percentual próximo daqueles oferecidos com unidades tendo três dormitórios que atingiam a média de $28 \%$, padrão não encontrado na oferta de imóvel com um único dormitório, que ficava na marca de $21 \%$.

Os bairros da Barra da Tijuca, Lagoa, Ipanema, Leblon e Gávea são aquelas localidades onde está concentrada a classe de renda alta, possuindo imóveis com quatro ou mais dormitórios, sendo compondo um quarto dos domicílios. Já nos subúrbios, em 1980, quase metade do estoque residencial disponível ofertava imóveis com dois dormitórios. O Centro apresentava um perfil habitacional destinado a solteiros e recém-casados ou a trabalhadores que aproveitavam a proximidade com os locais de emprego, ofertando imóveis com apenas um dormitório, sendo que parte deles se encontrava localizados em cortiços e vilas. $\mathrm{O}$ padrão instituído nas periferias seguia o perfil dos subúrbios, com domicílios com dois quartos, adequando-se ao novo modelo social dos habitantes dessa área.

O estoque residencial, portanto, apresentou quanto à estrutura imobiliária um padrão pouco diversificado, predominantemente com moradias de edifícios de apartamento com dois dormitórios, sendo que nas áreas periféricas o estoque de moradia era composto basicamente de casas, apresentando em média domicílios com dois dormitórios. Na década de 1980, o estoque imobiliário renovou-se, atendendo as necessidades do padrão de "sala e quarto", como também o tipo denominado "conjugado". Uma nova modalidade foi inserida no conceito de moradia, o padrão dos apart-hotéis, que indicava um estilo de vida moderno, alternativo e destinado a uma categoria econômica média alta, apresentando o boom imobiliário na década de 1980. 
Nas áreas periféricas, atendendo o padrão econômico dessa categoria, a habitação residencial continha apenas um dormitório, acentuando as altas taxas de densidade domiciliar vinculadas ao tamanho reduzido do imóvel. O mesmo fenômeno não é apresentado na periferia em expansão, cujos imóveis possuíam uma área maior do que as áreas periféricas, especialmente nos distritos mais rurais.

Conclui-se, portanto, que a qualidade do estoque imobiliário da Zona Sul, na década de 1980, consolidou o padrão de apartamentos, tendo pesados investimentos de médios e grandes empresas incorporadoras, sendo elementos indispensáveis para a valorização a localização e a qualidade de vida ofertada, contudo, não variando a sua dimensão daquelas apresentadas nos subúrbios e nas periferias. Contrasta-se o padrão habitacional de média a alta renda com a localização de assentamentos precários - as favelas.

A infraestrutura é o indicador mais importante para estabelecer o perfil socioespacial das condições de moradia na cidade do Rio de Janeiro. Em razão do auge no processo de industrialização na década de 1940 e na seguinte, grandes investimentos em infraestrutura básica foram alocados nos subúrbios e na região do Centro do Rio de Janeiro.

No caso da Barra da Tijuca, a partir dos anos de 1980, observa-se um processo de urbanização e instalação de infraestrutura, com investimentos pelo Poder Público municipal, atendendo os interesses dos grandes empreendedores imobiliários que aplicaram seu capital na área em expansão. Enquanto isso, a área de Santa Cruz foi destinada a abrigar as habitações precárias, com o perfil, inicialmente, como visto, sem atender as exigências legais.

A acessibilidade à moradia e a dinâmica imobiliária nos anos de 1980 apresentam como perfil a ocupação do estoque residencial composto por moradia própria, alugada ou cedida, às vezes irregular ou até mesmo ilegal. Os assentamentos informais localizados na Zona Sul da cidade assemelham-se àqueles oferecidos nas periferias e nos subúrbios, contudo, não guardando a propriedade formal qualquer relação com essas áreas do Rio de Janeiro, acentuando o quadro de segregação socioespacial. 
O crescimento da propriedade fundiária entre os vários segmentos sociais é resultado da queda em investimentos no setor de locação residencial, que apresenta decréscimo já na década de 1940. Nas regiões limítrofes, a malha urbana apresenta um quadro residencial derivado da forma de incorporação imobiliária urbana, reduzindo as práticas comerciais, acentuando o padrão de segregação e exclusão socioespacial da cidade do Rio de Janeiro nos anos de 1980, fruto das alterações na dinâmica intrametropolitana com a crise do período desenvolvimentalista e com a nova conjuntura política inaugurada na década de 1980.

\section{Considerações finais}

Os instrumentos de regularização fundiária são mecanismos de controle quanto à disponibilidade de oferta de terras por via da utilização compulsória das áreas vazias e subutilizadas. A participação popular reflete o ideal no planejamento urbano como meio de intervenção dos movimentos populares urbanos organizados com o devido apoio técnico dos especialistas visando à reforma urbana.

Contudo, a exploração da terra reflete, sob diversos ângulos, a cultura do capitalismo ressaltando o papel do solo como mercadoria, por meio da distribuição da riqueza, acentuando as desigualdades sociais como fenômeno resultante da constituição da estrutura espacial fortemente estratificada e segregada. A concentração na periferia da cidade de famílias que vivem no limite e/ou abaixo da chamada "linha da miséria" é a consequência imediata da valorização do solo em áreas nobres e da "expulsão" de parte da população que não tem recursos para adequar suas moradias aos padrões instituídos por lei. Portanto, a propriedade imobiliária é analisada como um fator que leva à valorização do capital na produção da moradia.

A atividade imobiliária na cidade é estabelecida tendo em vista a posição do setor empresarial em relação às formas de produção de moradia. Desse modo, o processo de inclusão do setor imobiliário é 
analisado sob a ótica da revalorização do capital nas mãos de poucos, relacionando o eixo socioeconômico de regulamentação da propriedade imobiliária e a integração entre os mecanismos de distribuição e gerenciamento do solo.

O solo, sob o ponto de vista do mercado imobiliário, é uma mercadoria. Nas cidades cujo perfil é o da supervalorização da terra urbana como um meio de multiplicação de lucro, o solo tem o papel de ser um instrumento rentável do "patrimônio arquitetônico-cultural" por meio da "revalorização urbana".

A desigualdade urbana é a soma das desigualdades de renda e de poder refletindo nas condições habitacionais e na valorização dos imóveis riqueza patrimonial das classes dominantes. A segregação constitui um reforço da articulação funcional das instituições da cidade na manutenção desse modelo urbano, limitando as possibilidades políticas de ruptura do modelo habitacional estabelecido. Assim, a exclusão territorial é também o reflexo das condições de habitação, relacionando-se com o conceito de exclusão social.

\section{Referências}

ABRAMO, P. Cidades em transformação: entre o plano e o mercado - experiências internacionais em gestão do solo urbano. Rio de Janeiro: UFRJ; IPPUR; Observatório Imobiliário de Políticas do Solo, 2001.

ARANTES, O. B. F. Uma estratégia fatal: a cultura nas novas gestões urbanas. In: ARANTES, O.; VAINER, C.; MARICATO, E. (Org.). A cidade do pensamento único: desmanchando consensos. Petrópolis: Vozes, 2000. p. 11-74.

BRASIL. Decreto-Lei n. 3.365, de 21 de junho de 1941. Dispõe sobre desapropriações por utilidade pública. Diário Oficial [da] República Federativa do Brasil, 18 jul. 1941. Disponível em: <http://www.planalto.gov.br/ccivil_03/decreto-lei/Del3365.htm>. Acesso em: 22 nov. 2011. 
BRASIL. Súmula n. 340, de 13 de dezembro de 1963. Desde a vigência do Código Civil, os bens dominicais, como os demais bens públicos, não poder ser adquiridos por usucapião. Disponível em: <http://www.stf.jus.br/portal〉. Acesso em: 22 nov. 2011.

BRASIL. Lei n. 4.504, de 30 de novembro de 1964. Dispõe sobre o Estatuto da Terra, e dá outras providências. Diário Oficial [da] República Federativa do Brasil, Poder Legislativo, Brasília, DF, 30 nov. 1964. Suplemento, p. 49. Disponível em: <http://www.planalto.gov.br/ccivil_03/leis/L4504.htm〉. Acesso em: 22 nov. 2011.

BRASIL. Lei n. 6.383, de 7 de dezembro de 1976. Dispõe sobre o Processo Discriminatório de Terras Devolutas da União, e dá outras providências. Diário Oficial [da] República Federativa do Brasil, Poder Legislativo, Brasília, DF, 9 dez. 1976. Disponível em: <http://www.planalto.gov.br/ccivil_03/leis/L6383. htm>. Acesso em: 22 nov. 2011.

BRASIL. Lei n. 6.969, de 10 de dezembro de 1981. Dispõe sobre a aquisição, por usucapião especial, de imóveis rurais, altera a redação do $\S 2^{\circ}$ do art. 589 do Código Civil e dá outras providências. Diário Oficial [da] República Federativa do Brasil, Poder Legislativo, Brasília, DF, Seção 1, 11 dez. 1981. p. 23.493. Disponível em: <http://www2.camara.gov.br/legin/fed/lei/1980-1987/ lei-6969-10-dezembro-1981-356622-norma-pl.html>. Acesso em: 22 nov. 2011.

BRASIL. Súmula n. 142, de 27 de setembro de 1983. A limitação administrativa "non aedificandi" imposta aos terrenos marginais das estradas de rodagem, em zona rural, não afeta o domínio do proprietário, nem obriga a qualquer indenização. Disponível em: <http://www.dji.com.br/normas_inferiores/sumula_tfr/ tfr_142.htm>. Acesso em: 22 nov. 2011.

BRASIL. Constituição (1988). Constituição: República Federativa do Brasil. Brasília: Senado Federal, 1988.

CARDOSO, A. L.; RIBEIRO, L. C. de Q. Dualização e reestruturação urbana: o caso do Rio de Janeiro. Rio de Janeiro: IPPUR/FASE - Observatório de Políticas Urbanas, 1996. 
DALLARI, A. A.; FERRAZ, S. (Org.). Estatuto da cidade. São Paulo: Malheiros, 2002.

IGLESIAS, F. Trajetória política do Brasil: 1500-1964. São Paulo: Companhia das Letras, 1993.

LAGO, L. C. do. Desigualdades e segregação na metrópole: o Rio de Janeiro em tempos de crise. Rio de Janeiro: Revan; Fase, 2000.

MACEDO SOARES, J. C. de. Fronteiras do Brasil no regime colonial. Rio de Janeiro: J. Olympio, 1939.

MEIRELLES, H. L. Direito administrativo brasileiro. 21. ed. São Paulo: Malheiros, 1996.

MONTEIRO, W. de B. Curso de direito civil. 6. ed. São Paulo: Saraiva, 1966.

NASCIMENTO, T. M. C. do. Introdução ao direito fundiário. Porto Alegre: Sergio Antonio Fabris, 1985.

PÓLIS, N. S. J., et al. (Org.). Assentamentos urbanos: Brasil século XXI - os caminhos da sustentabilidade cinco anos depois da Rio 92. Rio de Janeiro: Fase, 1997.

PRETECEILLE, E.; VALLADARES, L. Favela, favelas: unidade ou diversidade da favela carioca. In: RIBEIRO, L. C. Q. (Org.). O futuro das metrópoles: desigualdades e governabilidade. Rio de Janeiro: Revan/Observatório/IPPUR/UFRJFASE, 2000. p. 375-403.

REIS, N. G. Evolução urbana do Brasil: 1500-1720. 2. ed. São Paulo: Pini, 2000. RIBEIRO, L. C. de Q. Difusão e inovação da reforma urbana nos municípios brasileiros. Revista Proposta, Rio de Janeiro, n. 62, 1994.

RIBEIRO, L. C. de Q.; SANTOS Jr., O. A. dos. Globalização, fragmentação e reforma urbana: o futuro das cidades brasileiras na crise. Rio de Janeiro: Civilização Brasileira, 1994. 
RIBEIRO, L. C. de Q.; LAGO, L. C. do. Dinâmica metropolitana e novos padrões de desigualdade social. São Paulo em Perspectiva, v. 9, n. 2, p. 25-32, 1995.

SMOLKA, M. O.; AMBORSKI, D. Captura de mais-valias para o desenvolvimento urbano: uma comparação interamericana. In: ABRAMO, P. (Org.). Cidades em transformação: entre o plano e o mercado experiências internacionais em gestão do uso do solo urbano. Rio de Janeiro: Edição do Autor, 2001. p. 37-74. TEIXEIRA, F. M. P. Brasil: história e sociedade. São Paulo: Ática, 2000.

Recebido: 30/07/2011

Received: 07/30/2011

Aprovado: 20/08/2011 Approved: 08/20/2011 